\title{
Site Selection for Wind Farm Installation
}

\author{
G.C.Biswal ${ }^{1}$, S.P.Shukla ${ }^{2}$ \\ Department of Electrical Engineering, BIT, Durg, India ${ }^{1,2}$
}

\begin{abstract}
Wind energy offers significant potential for near-term (2020) and long-term (2050) greenhouse gas (GHG) emissions reductions. A number of different wind energy technologies are available across a range of applications, but the primary use of wind energy of relevance to climate change mitigation is to generate electricity from larger, gridconnected wind turbines, deployed either on- or offshore. On land as well as the Off-shore both are the possible choice for the wind farm developers. The off shore wind farms are considered better over the onshore counterpart due to various regions. They have more wind potential as it has stronger and more consistent wind profile. Among different criterions the selection of site is the first step for the wind farm developers. Various techniques are used for site identification of onshore/off shore/land based wind farms. It includes installation of a wind mast for several months / years and recording of relevant data and the other method is use of geographic information system (GIS), for data collection and analysis purpose. The objective of this paper is to apply the developed algorithms for selection of appropriate location for the installation of wind turbines. Matlab software (version R2011b) has been used for the implementation of the algorithm. The results are presented in graphical form and analyzed suitably.
\end{abstract}

Key Words: Site Selection, Geographic Information System, Wind Turbine.

\section{INTRODUCTION}

The selection of sites for wind farm development is not simply a matter of taking boxes on a list of desirable features .As with most things in life it is a matter of compromise and a cost benefit analysis of positive features against negative ones. The objective of this paper is to apply geographic information system (GIS) integrated with multi criteria decision making (MCDM) for effective site selection for large wind turbine. GIS has been designed to be as flexible as possible, allowing the user to specify which criteria will be used for the site selection, and if included what buffer distances to use around each excluded feature. The criteria include various parameters and exclusion factors such as: wind speed information, elevation, slope, highways and railways, built up area, forest zone and scenic area.

On the other hand, offshore wind farms are different from onshore wind farms in many respects and so the usual ways of thinking about the electrical aspects may not be appropriate. Clearly costs will be higher than on land. However, reliability and availability are also much more important, because faults may be more frequent and could take much longer to locate and repair. Unlike onshore public transmission and distribution networks, the relatively low capacity factors are likely to make full redundancy uneconomic. The restricted space and high cost of support structures offshore conflict with the need for additional switchgear to isolate faulty equipment. Within the offshore wind farm, the regular array may produce electrical system configurations different from the radial system typical of onshore wind farms. The wind farm monitoring or SCADA system also needs to be reconsidered. The main characteristics offshore are:

- larger arrays of larger machines;

- longer times to repair faults;

- less frequent scheduled maintenance;

- further to network connection points;

- more aggressive environment;
- less space available for equipment;

- Possibly a regular array with more freedom to choose cable routes.

\section{KEY FEATURES FOR SITE SELECTION OF A WIND FARM}

The site selected for wind farm development need to have many positive attributes including:

(i) Superior wind speed

(ii) Good road access to sites

(iii) Suitable terrain and geology for onsite access

(iv) Low population density

(v) Minimum risk of agro-forestry operations

(vi) Close to suitable electrical grid

(vii) Supportive land holders

(viii) Significant tourism infrastructure in place

(ix) Privately owned free hold land

(x) Good industrial support for construction and ongoing operations

(xi) Land use is primarily for grazing and cropping

(xii) Significant potential for revalidation

\section{DEVELOPMENT OF SOFTWARE PROGRAM AND SITE RESOURCE ANALYSIS}

A Matlab program was developed for selection of the most suitable site for the wind tower installation. The program has been developed in Matlab Version R2011b. Approximate data collection was done at six different possible wind farm sites in the state of Chhattisgarh and neighboring states. Main parameters of interest are month, date and time of data collection, average wind velocity, temperature, air density, height of measurement of wind velocity etc. The data has been analyzed and presented in suitable GUI (Graphical User Interface) format. Figure 1 to figure 6 represents the wind speed distribution for selected sites corresponding to number 1 to number 7 at the height of 80 meters. 
INTERNATIONAL JOURNAL OF INNOVATIVE RESEARCH IN ELECTRICAL, ELECTRONICS, INSTRUMENTATION AND CONTROL ENGINEERING

Vol. 3, Issue 8, August 2015

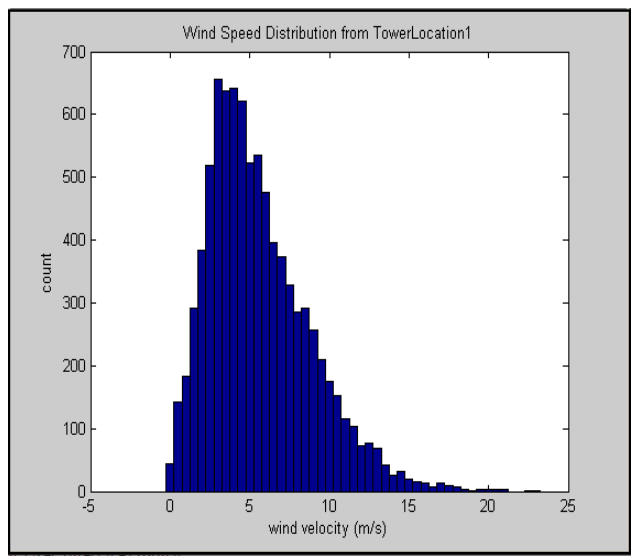

Figure 1: Wind Speed Distribution Location 1

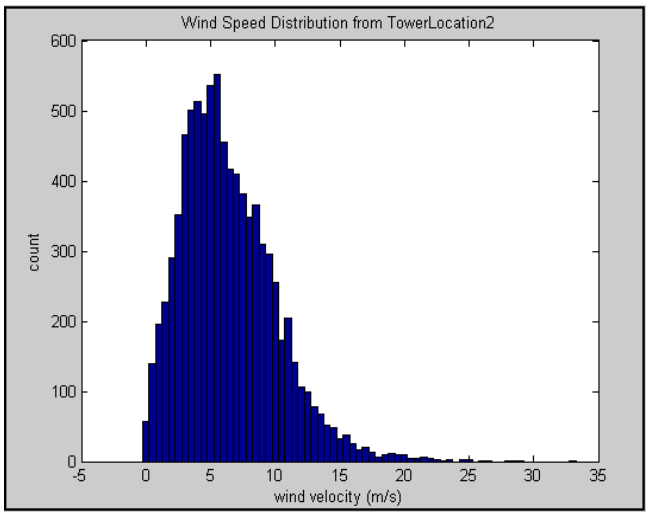

Figure 2: Wind Speed Distribution Location 2

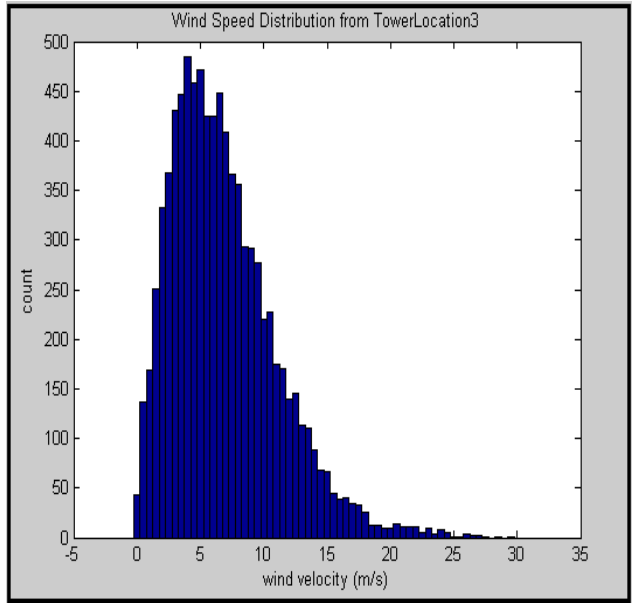

Figure 3: Wind Speed Distribution Location 3

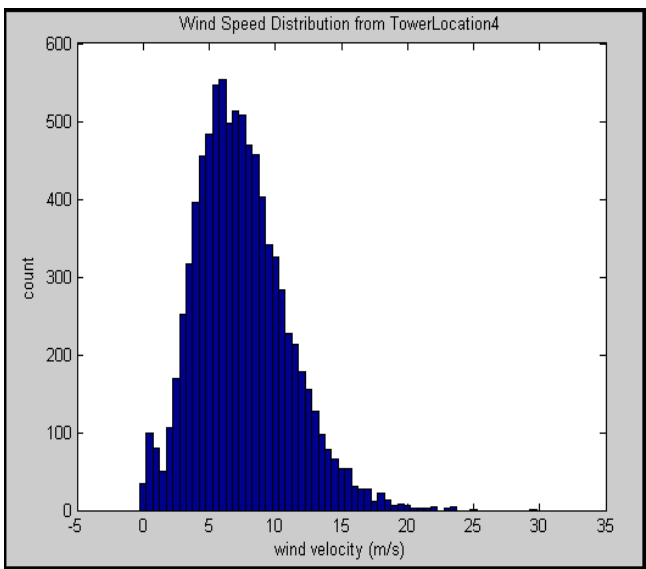

Figure 4: Wind Speed Distribution Location 4

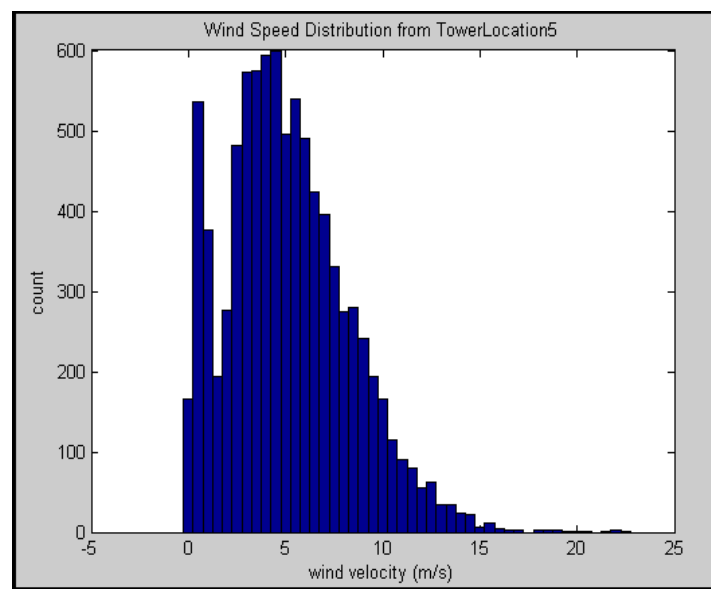

Figure 5: Wind Speed Distribution Location 5

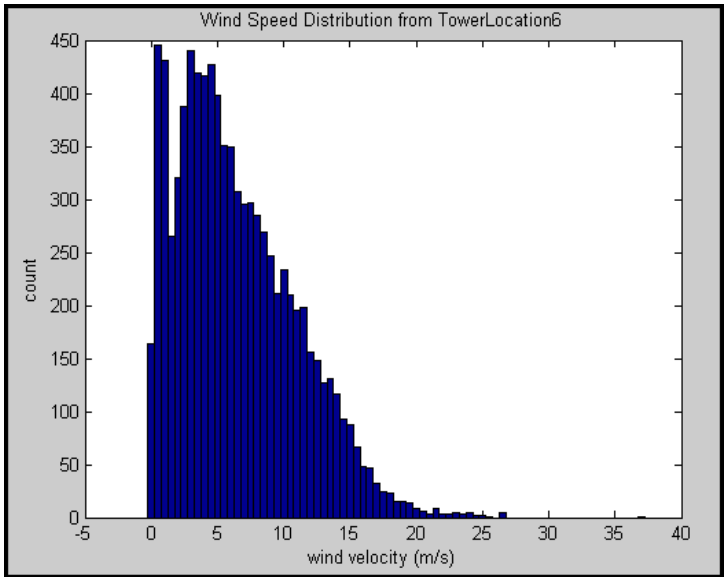

Figure 6: Wind Speed Distribution Location 6

From the analysis of above figures the capacity factor for each site was calculated. It was found that site 1 has more counts nearer to and below 5 meters/seconds. The site 2 has more counts between 6 to 7 meters/seconds. The site 3 has more counts of about 3 meters/second and fewer counts above 5 meters/seconds. The site 4 has more counts in the range of 8 to 10 meters/seconds. The site 5 has more counts of about 3 meters/second and fewer counts above 5 meters/seconds. Similarly the site 6 has dense counts near 3 meters/second and fewer counts above 5 meters/seconds. Since the site 4 has more counts above the cut-in wind velocity among the selected 06 sites, it is the best location for the installation of wind turbine. It is shown in figure 7 below.



Figure 7 : Identification of Best Site Location 


\section{RESOURCE ANALYSIS AT LOCATION 4}

Figure 8 and 9 represents the temperature and the wind velocity recorded at the location 4 which is found as the most suitable site. Temperature is shown in degree centigrade and wind velocity in meter per second at 80 meter hub height.

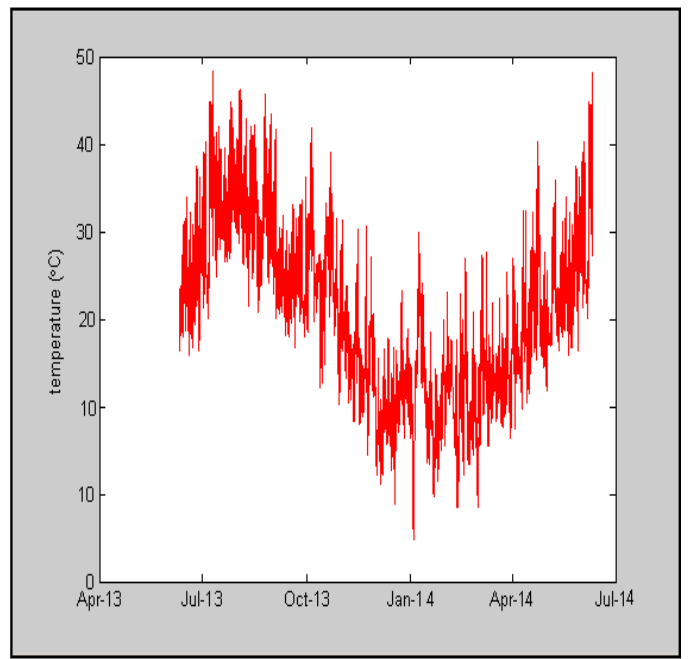

Figure 8: Temperature Variation at location 4

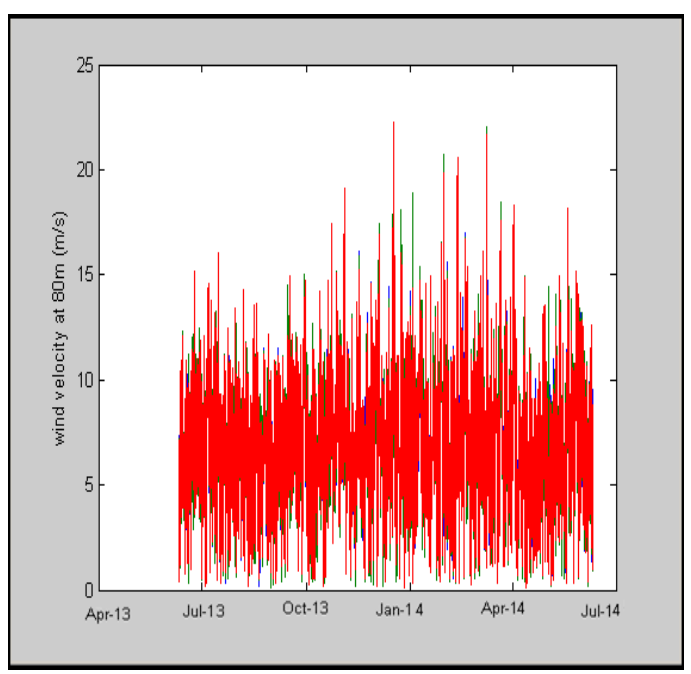

Figure 9: Wind Velocity Variation at location 4

Figure 10 below represents the input wind velocity $(\mathrm{m} / \mathrm{s})$ versus output power (MW). With the rated capacity of $1 \mathrm{MW}$ generator (assumed), about $4.5 \mathrm{~m} / \mathrm{s}$ is the cut-in velocity, $12 \mathrm{~m} / \mathrm{s}$ is the rated velocity and $22 \mathrm{~m} / \mathrm{s}$ is considered as cut-off wind velocity .

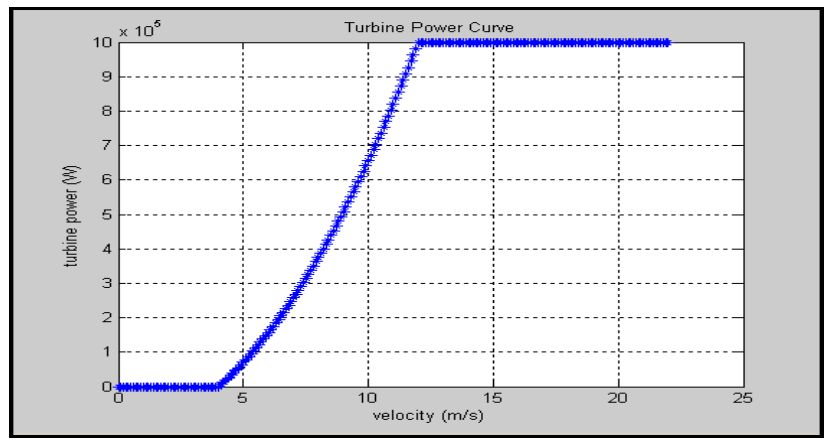

Figure 10: Output Power Variation for a turbine at location 4

\section{CONCLUSION}

The total energy consumption is exponentially increasing worldwide. The wind energy project is one of the most possible ways for sustainable energy development. Since the cost of large wind turbine project is rather high, the project feasibility should be done before construction of the large wind turbine project. Selecting the site for wind turbine positions is a complex process involving not only technical requirement, but also physical, economical, social, environmental and political requirements that may result in conflicting objectives. Such complexities necessitate the simultaneous use of several decision support tools such as high spatial resolution remotely sensed data, Geographical Information System and Multi Criteria Decision Making. This shows that the extremely suitable sites have wind velocity in the range of $8 \mathrm{~m} / \mathrm{s}$ to $15 \mathrm{~m} / \mathrm{s}$ at $80 \mathrm{~meter}$ height. This is corresponding to the wind power graphs discussed earlier. This results in the high scarcity of appropriate sites. Therefore, it is necessary to find more suitable sites for the installation of wind turbines. This is possible with the help of more favorable policies from the government and private sectors and keen interest of researchers and the public as well.

\section{REFERENCES}

[1] Adul Bennui Et Al, "Site Selection or Large Wind Turbine Using GIS" PSU-UNS International Conference On Engineering And Environment - ICEE-2007, Phuket May 10-11, 2007 Prince Of Songkla University, Faculty Of Engineering Hat Yai, Songkhla, Thailand 90112

[2] R. Mani Murli et al, "site selection for offshore wind farms along the Indian sea coast" Indian journal of marine sciences, vol. 43(7), July 2014.

[3] Bundled Wind Power Projects in Satara \& Supa (Maharashtra in India) managed by Tata Motors Ltd. UNFCCC registration reference number: 0744 Monitoring Report From 1/04/2008 to 31/03/2009 Version 04,14 th May 2010.

[4] Kim Hyong Sik et al (2010). "Wind Energy Conversion System from Electrical Perspective A Survey" Smart Grid and Renewable Energy, 2010, 1, 119-131

[5] Mathew S, Pandey K.P., Anil K.V. (2002). "Analysis of wind regimes for energy estimation” Renewable Energy 25:381-399.

[6] Yeliz MK, Ilhan U (2008). Analysis of wind speed distributions: Wind distribution function derived from minimum cross entropy principles as better alternative to Weibull function Energy Conversion and Management 49(5):962-973.

[7] Albers A., Gerdes, G( 2007). Micrositing of Small-scale Wind Turbines is Economically Viable for Rural Electrification in Sri Lanka. DEWI Magazine (1999); 14: p.24-35. 